\title{
Alterations to Nuclear Architecture and Genome Behavior in Senescent Cells
}

\author{
ISHITA S. MEHTA, ${ }^{a}$ MARTIN FIGGITT, ${ }^{b}$ CRAIG S. CLEMENTS, ${ }^{b}$ \\ IAN R. KILL, ${ }^{b}$ AND JOANNA M. BRIDGER ${ }^{a}$ \\ ${ }^{a}$ Laboratory of Nuclear and Genomic Health, Centre for Cell and Chromosome \\ Biology, Biosciences, School of Health Sciences and Social Care, \\ Brunel University, West London UB8 3PH, United Kingdom \\ ${ }^{b}$ Laboratory of Cellular Gerontology, Centre for Cell and Chromosome Biology, \\ Biosciences, School of Health Sciences and Social Care, Brunel University, \\ West London UB8 3PH, United Kingdom
}

\begin{abstract}
The organization of the genome within interphase nuclei, and how it interacts with nuclear structures is important for the regulation of nuclear functions. Many of the studies researching the importance of genome organization and nuclear structure are performed in young, proliferating, and often transformed cells. These studies do not reveal anything about the nucleus or genome in nonproliferating cells, which may be relevant for the regulation of both proliferation and replicative senescence. Here, we provide an overview of what is known about the genome and nuclear structure in senescent cells. We review the evidence that nuclear structures, such as the nuclear lamina, nucleoli, the nuclear matrix, nuclear bodies (such as promyelocytic leukemia bodies), and nuclear morphology all become altered within growth-arrested or senescent cells. Specific alterations to the genome in senescent cells, as compared to young proliferating cells, are described, including aneuploidy, chromatin modifications, chromosome positioning, relocation of heterochromatin, and changes to telomeres.
\end{abstract}

KEYWORDS: senescence; chromosome positioning; nuclear architecture; laminopathies; genome organization

\section{INTRODUCTION}

Cellular senescence is a state of viable growth arrest arrived at after repeated passage in culture. For any cell strain, senescence is reached after a finite and predictable number of population doublings. The process leading to senescence arrest (termed replicative senescence) is characterized by the gradual

Address for correspondence: Joanna M. Bridger, Laboratory of Nuclear and Genomic Health, Centre for Cell and Chromosome Biology, Biosciences, School of Health Sciences and Social Care, Brunel University, West London, UB8 3PH, UK. Voice: ++44-1895-266272; fax: ++44-1895-274348.

Joanna.bridger@brunel.ac.uk

Ann. N.Y. Acad. Sci. 1100: 250-263 (2007). (C) 2007 New York Academy of Sciences. doi: 10.1196/annals.1395.027 
accumulation of nondividing cells throughout the reproductive life span of the culture. ${ }^{1}$ It has been suggested that the process of cellular senescence is linked to the process of organismal aging, and indeed a number of studies have shown that senescent cells accumulate within tissues with increasing chronological age. ${ }^{2-4}$ Senescent cells display an altered phenotype compared with their proliferative antecedents ${ }^{5,6}$ revealing a functional change in genome behavior. We are interested in the changes in senescent cells and how this may be influenced by alterations in genome organization.

The nucleus houses and protects the genome and further influences and controls the function of the genome. For many decades, due to limited understanding of this organelle, it was termed the "black box" of the cell. ${ }^{7}$ However, in the last few decades there have been many new advances in techniques, such as microscopy and molecular biology, allowing us to understand more and more about how the nucleus is organized and how it functions.

The nucleus is compartmentalized, comprising a number of nuclear structures and regions that manage restricted nuclear activities. The structural components of the nucleus are intimately linked to the genome allowing signaling and ultimately control of the genome function. ${ }^{8}$ These nuclear structures include the nuclear envelope, nucleoli, nuclear bodies, and the nuclear matrix (FIG. 1). Misorganization or defects in nuclear structures and/or architecture are associated with cancer and severe premature aging diseases, such as the progeroid syndromes and laminopathies. ${ }^{9}$ Thus, it is important that we fully understand how the nucleus and the genome functions in aged and senescent cells.

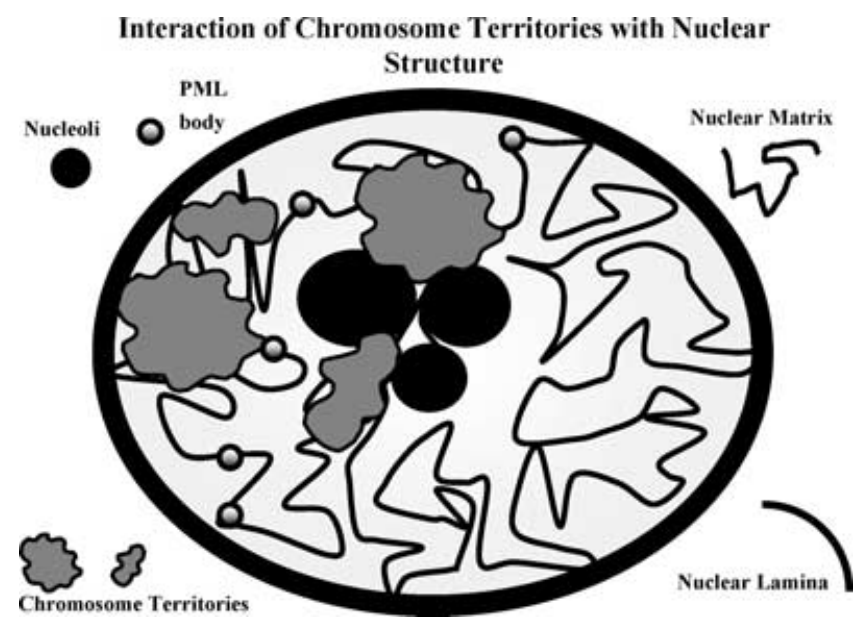

FIGURE 1. A diagram displaying some of the components of an interphase nucleus, that is, the nuclear lamina, nucleoli, the nuclear matrix, PML bodies, and chromosome territories. 
The genome is organized within the nucleus as whole chromosomes. There are many influences on the genome to regulate gene expression, including epigenetic modifications, such as methylation and acetylation, which alter chromatin behavior. ${ }^{10-12}$ Furthermore, the actual location of the chromatin, how it associates with nuclear structures and even other regions of the genome are also factors in controlling transcriptional capabilities of a genomic region. ${ }^{11,13}$ Thus, intricate properties of chromosomes, including organization, spatial location, interaction with nuclear architecture as well as various epigenetic phenomena, work together to ensure that transcription is correctly regulated. ${ }^{14,15}$

\section{CHANGES IN THE MORPHOLOGY OF SENESCENT CELLS}

It is clear from simple microscopical observations that the morphology of cells change during cellular aging. Indeed, senescent fibroblasts become much larger and lose their elongated spindle-like qualities, becoming much more amorphous in shape and no longer bipolar. ${ }^{16-18}$

Senescent cells also have larger nuclei. This is demonstrated here by a study, where human dermal fibroblasts (NB1 cell strain $\left.{ }^{19}\right)$ were fixed at early $(<10 \%$ life span completed) or late ( $>95 \%$ life span completed) passage, stained, imaged and their nuclear area measured digitally. FIGURE 2 shows a frequency distribution plot of nuclear area of cells in early and late passage cultures. There is a shift in both the mean and median nuclear area between the two groups (mean $=255 \mu \mathrm{m}^{2}$ early passage, $293 \mu \mathrm{m}^{2}$ late passage; median $=240 \mu \mathrm{m}^{2}$ early passage, $285 \mu \mathrm{m}^{2}$ late passage) revealing that cellular aging is characterized by a shift in nuclear area toward larger nuclei.

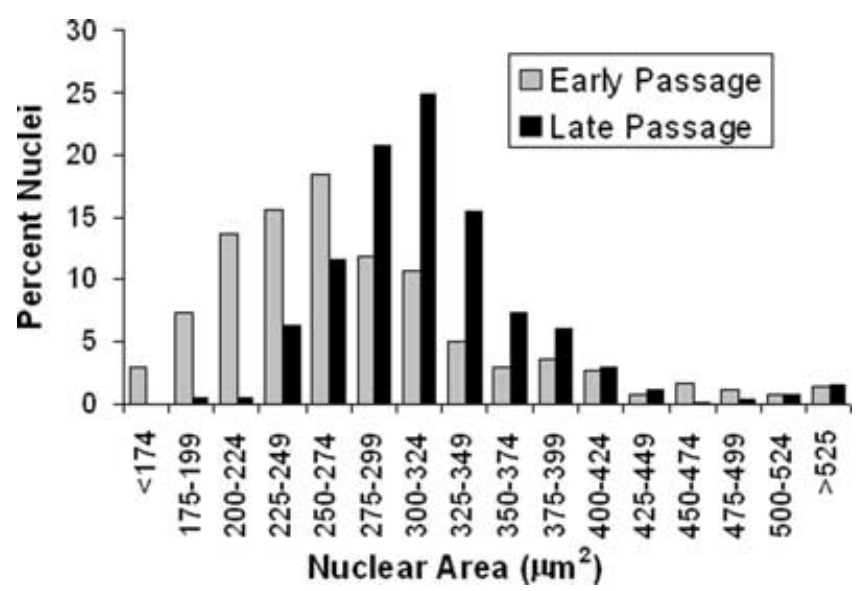

FIGURE 2. Frequency distribution plot of nuclear area size categories from human dermal fibroblasts in early or late passage cultures. 


\section{CHANGES IN CHROMATIN IN SENESCENT CELLS}

Efficient transcription of a genome requires a combination of compact packaging of the chromatin within the constraints of the nucleus and accessibility of the region of the genome that is to be transcribed. ${ }^{20}$ The genome is packaged as less compact, more open, euchromatin, and more condensed heterochromatin consisting of facultative and constitutive heterochromatin. Euchromatin has commonly been associated with transcriptionally active regions of the genome, although there are inactive genes found within open chromatin and actively transcribed genes within compact chromatin. ${ }^{21}$

It appears that there is spatial relocation of silenced genes to regions of heterochromatin within nuclei but it is not yet clear how spatial relocalization to repressed regions of the nucleus is specifically involved in gene silencing. ${ }^{22}$

Heterochromatin formation has been closely studied in senescent cells by Narita et al. ${ }^{23}$ This study revealed the formation of senescence-associated heterochromatic foci (SAHF). These are regions that contain the heterochromatic protein HP1, heterochromatic markers, and high mobility group A proteins. These heterochromatic structures may have a role in transcriptional repression of proliferation-associated genes. The SAHF are enriched in a transcriptionally repressive variant of $\mathrm{H} 2 \mathrm{~A}$, macroH $2 \mathrm{~A} \cdot{ }^{24,25}$ Histones may be an important facilitator of genome behavior in senescent cells since an earlier study revealed that in senescent cells there is a decrease in the synthesis of histone H1, leading to less H1 in aged cells. ${ }^{26}$

Recent evidence has associated chronological age with an increase in heterochromatinization of regions of the genome within human lymphocytes. Lezhava demonstrates a higher percentage of condensed chromatin in interphase nuclei of cells derived from older people ( $80-93$ years) as compared to cells derived from younger people (25-52 years). ${ }^{27}$ Further, the transcriptional activity of the old cells with higher levels of heterochromatinization was observed to have decreased as compared to younger or middle-aged cells.

Thus, there appears to be a common link between increased heterochromatinization in senescence and organismal aging suggesting that the two processes are related.

DNA methylation of genomic regions at cytosine residues is another epigenetic phenomenon involved in gene silencing and thus in the regulation of gene transcription. Methylation is also thought to be an important feature during the transition of the cell from a proliferating state to a senescent state. ${ }^{28,29}$ Indeed, hypermethylation may cause heterochromatinization and thus would result in gene silencing. ${ }^{30}$

It is not yet clear how methylation plays a role in aging, but this epigenetic factor does seem to be an important target for future studies. ${ }^{28}$ However, cells derived from the premature aging disease Werner Syndrome, may be 
an interesting model to use in the study of senescence-like DNA methylation patterns. ${ }^{31}$

\section{TELOMERES AND THEIR ROLE IN SENESCENT CELLS}

Telomeres are DNA sequences found at the ends of chromosomes. They bind nucleoproteins, protect chromosome ends from degradation and endto-end fusions, and mediate the process of chromosomal replication. ${ }^{32}$ Each telomere comprises kilobases of hexameric repeats and a 3'overhang of 100400 nucleotides at their ends, ${ }^{33,34}$ forming a T-loop structure that is stabilized by telomeric proteins. The combination of DNA with proteins bound to it forms the protective telomere cap.

Telomeres may act as a "replicational" clock that keeps track of the number of cell divisions a cell has undergone, as with each cycle of DNA replication, a small part of the overhanging DNA that forms the ends of the telomeres is lost. ${ }^{35,36}$ Thus, cells undergo divisions until they reach a state termed as "senescence erode" which is characterized by shortening of the telomere to half of its original size..$^{35,37}$ Thus, telomere shortening or attrition has been accepted as one of the major hallmarks of aging cells. ${ }^{35}$ However, recent insights have proposed that telomere length per se is not as important as the capped state of telomeres, ${ }^{38}$ and that uncapped telomeres lead to a protective double-strand break repair response inducing cells to enter the senescent state. ${ }^{39}$

\section{CHANGES IN NUCLEAR ARCHITECTURE IN SENESCENT CELLS}

\section{Nucleoli}

The nucleolus is the site of synthesis, processing, and maturation of preribosomal particles. However, recent evidence has demonstrated roles for the nucleolus in aging, proliferation control, and stress responses. ${ }^{40}$ Nevertheless, the nucleolus remains the paradigm for structure-function relationships in the nucleus. ${ }^{41}$

The nucleolus undergoes several changes as a cell ages; some of which have implications on its function. An initial visual comparison between the nucleoli of senescent and presenescent cells is that senescent cells have a single but larger nucleolus whereas presenescent cells show a higher number of small nucleoli. ${ }^{42}$

There are a number of proteins, which are involved in cellular senescence that reside in the nucleoli. Proteins, such as p14 ARF and nucleophosmin, are present in the nucleolus as well as the nucleoplasm, and are involved in releasing and facilitating $\mathrm{p} 53$ stability. ${ }^{43,44}$ 
Thus, the nucleolus is not only affected by the process of cellular senescence, but may play a role in the process of replicative senescence.

\section{Nuclear Matrix}

The nuclear matrix/nucleoskeleton is a filamentous network of protein, DNA, and RNA that remains in nuclei when cells are treated with high salt and nucleases. ${ }^{45,46}$ This structure, made up of $10 \mathrm{~nm}$ filaments, anatomizes through the nucleoplasm and is thought to provide structural support to the nucleus. It is also involved in defining the nuclear size and shape. ${ }^{11}$

The nuclear matrix serves as a skeleton for the nucleus and is the structure that supports DNA replication, transcription, and repair, ${ }^{11}$ RNA splicing and transport, ${ }^{46}$ maintaining the strict compartmentalization of the nucleus, ${ }^{47,48}$ and providing an architectural scaffolding for higher-order chromatin packaging. ${ }^{49}$ Some components that associate or constitute the nuclear matrix include nuclear lamins..$^{50-52}$

Two-dimensional electrophoretic analysis of the synthesis of nuclear matrix proteins from presenescent and senescent human fibroblasts revealed several changes in nuclear matrix composition between the two cell types. ${ }^{53}$ In particular, the level of synthesis of an unidentified 47-kDa peptide was cell cycle regulated in presenescent cells and synthesized at constitutively high levels in senescent cells.

The nuclear matrix appears to anchor the genome through telomeres, ${ }^{54-56}$ centromeres, ${ }^{57,58}$ and matrix attachment regions. ${ }^{59}$ Interestingly, it has been shown that the nuclear matrix could not bind the TRF1 protein found at telomeres in primary fibroblasts but could in immortal fibroblasts. ${ }^{60}$ Hence alterations to binding of nuclear matrix and telomeres could affect the cells progression into the cell cycle as well as the entry of the cell into senescence. ${ }^{55,61}$ Telomere anchoring is very important for the repair of DNA breaks occurring in these regions, thus, any disruption to this binding can result in inability of the cell to repair DNA damage and thereby would cause the cell to undergo apoptosis or senescence.

Bickmore and colleagues demonstrated that the gene-rich chromosome HSA 19 was always tethered to the nuclear matrix when nuclear matrices were prepared from human lymphoblasts and fibroblasts without the use of DNA nuclease; while the gene-poor chromosome HSA 18 appeared to be dispersed away from the residual nucleus in the DNA halo. ${ }^{62}$

\section{Nuclear Lamina}

The nucleus is separated from the cytoplasm by a nuclear envelope made up of inner and outer nuclear membranes, nuclear pore complexes, and the lamina. 
The inner nuclear membrane binds a set of integral and membrane-associated proteins and protein complexes that can bind to chromatin. ${ }^{63}$ Underlying the inner nuclear membrane is a network of lamin polymers that form a meshwork of filaments called the nuclear lamina, ${ }^{64}$ which maintains nuclear integrity and tethers specific regions of the genome to the nuclear periphery. ${ }^{8}$

The major components of the nuclear lamina are the type- $\mathrm{V}$ intermediate filament A- and B-type lamin proteins ${ }^{65}$ which interact with the nuclear membrane, integral membrane proteins, chromatin binding proteins, and soluble proteins. ${ }^{66,67}$ Nuclear lamins are vital for chromatin organization, ${ }^{68-70}$ DNA replication, ${ }^{71}$ RNA polymerase II-dependent gene expression, ${ }^{72}$ and bridging the gap between the nucleoskeleton and the cytoskeleton. ${ }^{73}$

B-type lamins appear to be essential for survival in vivo since mice engineered with mutations in lamin B are able to complete development but die shortly after birth. ${ }^{74}$ Fibroblast cultures derived from embryos harboring the mutations display a variety of aberrant cellular phenotypes including premature senescence and display grossly misshapen nuclei. Overexpression of lamin B1 in humans causes autosomal dominant leukodystrophy. ${ }^{75}$

On the other hand, loss of A-type lamins in vivo does not seem to affect development and mice lacking A-type lamins survive beyond birth. However, 3 weeks after birth the mice developed muscular dystrophies, loss of white fat, thymic atrophy, growth retardation, and a disruption to spermatogenesis. ${ }^{69,76}$ Mutations in A-type lamins can result in a wide range of diseases termed "laminopathies" (for review see Ref. ${ }^{77}$ ). Among these diseases are two segmental progeroid syndromes, Hutchinson Gilford Progeria Syndrome (HGPS) and Atypical Werner Syndrome (AWS). In vitro studies have revealed that perturbations to the A-type lamina have profound effects upon both nuclear structure and function including premature cellular senescence and increased rates of apoptosis. ${ }^{19}$

During the process of cellular aging in normal fibroblasts, there is an increase in the fraction of cells displaying gross abnormalities in nuclear shape. This accumulation appears to be exaggerated in laminopathy cells and may be linked with premature senescence $^{19}$ (Mehta I.S., Figgitt M., Meaburn K.J., Kill I.R., Bridger J.M., unpublished).

Indeed, there is some evidence that accumulation of abnormal nuclei occurs with human aging in vivo. ${ }^{78}$

\section{Promyelocytic Leukemia Bodies}

Promyelocytic leukemia (PML) bodies are known to have an influence on cell cycle progression and to an extent on cellular senescence. ${ }^{79}$

PML bodies are spherical bodies found scattered throughout the nucleoplasm attached to the nuclear matrix, ${ }^{80}$ outside chromosome territories. ${ }^{81}$ The structure and stability of these nuclear bodies seem to be highly dependent on the integrity of the chromatin they associate with. ${ }^{82}$ These nuclear structures 


\section{Young Proliferating Cell Nucleus}

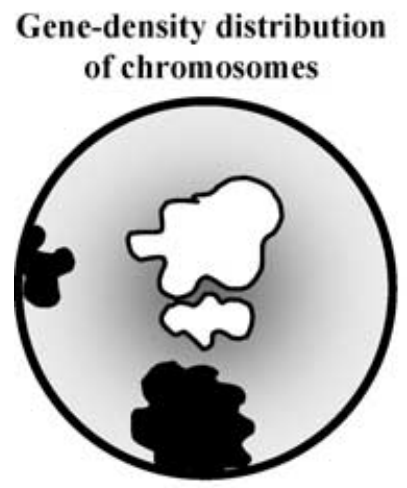

Gene-Poor
Chromosomes

\section{Senescent Cell}

Nucleus

Size distribution

of chromosomes

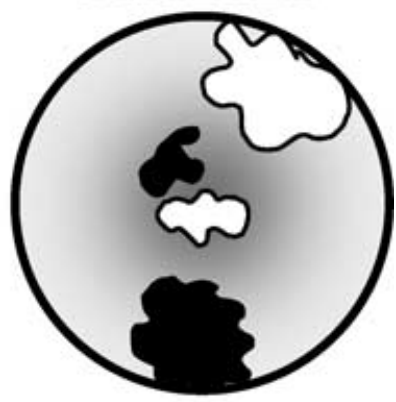

Gene-Rich

Chromosomes

FIGURE 3. A model demonstrating the repositioning of chromosomes when human dermal fibroblasts become senescent. The positions of chromosomes change from a genedensity correlated radial position to a size correlated radial position.

play vital roles in DNA replication and repair, cell cycle control, apoptosis, ${ }^{83,84}$ and in gene transcription. ${ }^{85-87}$ PML bodies also associate with very specific parts of the genome; they have been found to be clustered near gene-rich and transcriptionally active regions of the genome ${ }^{88,89}$ but may also be involved in gene repression. ${ }^{90}$

Their association with the genome is very dynamic and changes as the cell progresses through the cell cycle. ${ }^{89}$ PML bodies are also involved in the process of cellular senescence either via $\mathrm{p} 53^{91,92}$ or via hypophosphorylated pRB pathways. ${ }^{93}$

\section{CHANGES IN CHROMOSOME BEHAVIOR IN SENESCENT CELLS}

Chromosomes in interphase nuclei occupy their own individual chromosome territories, ${ }^{94-97}$ which are irregularly shaped and largely immobile at submicron level..$^{98-100}$

Current models of nuclear organization support the idea that chromosomes in the interphase nucleus are arranged nonrandomly, in a radial organization, with each chromosome occupying a discrete area of the nucleus. ${ }^{13,62,101-104}$

Analyses from a number of laboratories demonstrate that radial chromosomal positioning in proliferating interphase nuclei is correlated with gene density. ${ }^{62,101,105-107}$ This theory suggests that chromosomes are organized radially 
with gene-rich chromosomes grouped in the nuclear interior while gene-poor chromosomes are located at the nuclear periphery. Interestingly, as cells enter a nonproliferating state, either senescence or quiescence, chromosomes become relocalized within nuclei, but still maintain a radial distribution. ${ }^{102}$ We have found that chromosomes are positioned in senescent cells according to a sizerelated distribution (Mehta I.S., Figgitt M., Meaburn K.J., Kill I.R., Bridger J.M., unpublished). This indicates that a number of small chromosomes move from the nuclear periphery to the nuclear interior and other larger chromosomes move to the nuclear periphery from a more internal nuclear location (see FIG. 3). Furthermore, the position of specific chromosomes in proliferating nuclei of laminopathy cells is altered and resembles that of normal senescent cells. ${ }^{108}$ How this repositioning of chromosomes affects gene expression or function is as yet unknown. However, given that young laminopathy cells behave in some regards as aged normal cells, this implies that A-type lamins are involved in normal cellular senescence. ${ }^{77}$

Another similar phenomenon concerning the genome behavior in senescent cells ${ }^{18,109,110}$ and laminopathy cells ${ }^{111}$ is aneuploidy. This could of course severely affect cellular functions in normal senescent cells and in young proliferating cells of laminopathy patients.

In summary, the genome and the nuclear architecture it interacts with undergo dramatic changes as cells enter senescence, leading to major alterations in genome function in senescent cells.

\section{REFERENCES}

1. Kill, I.R., R.G. Faragher, K. Lawrence \& S. Shall. 1994. The expression of proliferation-dependent antigens during the lifespan of normal and progeroid human fibroblasts in culture. J. Cell. Sci. 107(Pt 2): 571-579.

2. DiMRI, G.P. et al. 1995. A biomarker that identifies senescent human cells in culture and in aging skin in vivo. Proc. Natl. Acad. Sci. USA 92: 9363-9367.

3. LI, Y., Q. YAN \& N.S. Wolf. 1997. Long-term caloric restriction delays agerelated decline in proliferative capacity of murine lens epithelial cells in vitro and in vivo. Invest Ophthalmol Vis. Sci. 38: 100-107.

4. Pawelec, G., W. Wagner, M. Adibzadeh \& A. Engel. 1999. T cell immunosenescence in vitro and in vivo. Exp. Gerontol. 34: 419-429.

5. CAmpisI, J. 1998. The role of cellular senescence in skin aging. J. Investig. Dermatol. Symp. Proc. 3: 1-5.

6. Faragher, R.G. \& D. Kipling. 1998. How might replicative senescence contribute to human ageing? Bioessays 20: 985-991.

7. van Driel, R., B. Humbel \& L. DE Jong. 1991. The nucleus: a black box being opened. J. Cell. Biochem. 47: 311-316.

8. Bridger, J.M., N. Foeger, I. R. Kill \& H. Herrmann. 2007. The Nuclear Lamina-A structural framework involved in genome organisation. FEBS J. (In Press). 
9. Foster, H.A. \& J.M. Bridger. 2005. The genome and the nucleus: a marriage made by evolution. Genome organisation and nuclear architecture. Chromosoma 114: 212-229.

10. BECKeR, P.B. 2002. Nucleosome sliding: facts and fiction. EMBO J. 21: 47494753.

11. JACKSON, D.A. 2003. The principles of nuclear structure. Chromosome Res. 11: $387-401$.

12. Jenuwein, T. \& C.D. Allis. 2001. Translating the histone code. Science 293: 1074-1080.

13. Cremer, T. \& C. Cremer. 2001. Chromosome territories, nuclear architecture and gene regulation in mammalian cells. Nat. Rev. Genet. 2: 292-301.

14. Misteli, T. 2004. Spatial positioning; a new dimension in genome function. Cell 119: $153-156$.

15. Misteli, T. 2005. Concepts in nuclear architecture. Bioessays 27: 477-487.

16. Bowman, P.D. \& C.W. DANIEL. 1975. Aging of human fibroblasts in vitro: surface features and behavior of aging WI 38 cells. Mech. Ageing Dev. 4: 147-158.

17. Mitsui, Y. \& E.L. SCHNEIDER. 1976. Increased nuclear sizes in senescent human diploid fibroblast cultures. Exp. Cell Res. 100: 147-152.

18. Sherwood, S.W., D. Rush, J.L. Ellsworth \& R.T. Schimke. 1988. Defining cellular senescence in IMR-90 cells: a flow cytometric analysis. Proc. Natl. Acad. Sci. USA 85: 9086-9090.

19. BRIDGER, J.M. \& I.R. KILL. 2004. Aging of Hutchinson-Gilford progeria syndrome fibroblasts is characterised by hyperproliferation and increased apoptosis. Exp. Gerontol. 39: 717-724.

20. Avramova, Z.V. 2002. Heterochromatin in animals and plants. Similarities and differences. Plant Physiol. 129: 40-49.

21. GILBERT, N. et al. 2004. Chromatin architecture of the human genome: gene-rich domains are enriched in open chromatin fibers. Cell 118: 555-566.

22. Fisher, A.G. \& M. MerkensChlager. 2002. Gene silencing, cell fate and nuclear organisation. Curr. Opin. Genet. Dev. 12: 193-197.

23. NARITA, M. et al. 2003. Rb-mediated heterochromatin formation and silencing of E2F target genes during cellular senescence. Cell 113: 703-716.

24. SChUlz, L. \& J. TYler. 2005. Heterochromatin focuses on senescence. Mol. Cell 17: $168-170$.

25. ZHANG, R. et al. 2005. Formation of MacroH2A-containing senescenceassociated heterochromatin foci and senescence driven by ASF1a and HIRA. Dev. Cell 8: 19-30.

26. Mitsui, Y., H. Sakagami, S. Murota \& M. Yamada. 1980. Age-related decline in histone $\mathrm{H} 1$ fraction in human diploid fibroblast cultures. Exp. Cell. Res. 126: 289-298.

27. Lezhava, T. 2001. Chromosome and aging: genetic conception of aging. Biogerontology 2: 253-260.

28. HollidaY, R. 1985. The significance of DNA methylation in cellular aging. Basic Life Sci. 35: 269-283.

29. Smeal, T. \& L. Guarente. 1997. Mechanisms of cellular senescence. Curr. Opin. Genet. Dev 7: 281-287.

30. MAzIN, A.L. 1994. Enzymatic DNA methylation as an aging mechanism. Mol. Biol. Mosk 28: 21-51.

31. Agrelo, R. 2007. A new molecular model of cellular aging based on Werner syndrome. Med Hypotheses 68: 770-780. 
32. ZHU, X. et al. 1996. Cell cycle-dependent modulation of telomerase activity in tumor cells. Proc. Natl. Acad. Sci. USA 93: 6091-6095.

33. Griffith, J.D. et al. 1999. Mammalian telomeres end in a large duplex loop. Cell 97: 503-514.

34. Wellinger, R.J. \& D. Sen. 1997. The DNA structures at the ends of eukaryotic chromosomes. Eur. J. Cancer 33: 735-749.

35. Harley, C.B., A.B. Futcher \& C.W. Greider. 1990. Telomeres shorten during ageing of human fibroblasts. Nature 345: 458-460.

36. STEWART, S.A. et al. 2003. Erosion of the telomeric single-strand overhang at replicative senescence. Nat. Genet. 33: 492-496.

37. Allsopp, R.C. et al. 1995. Telomere shortening is associated with cell division in vitro and in vivo. Exp. Cell. Res. 220: 194-200.

38. BlackBurN, E.H. 2000. Telomere states and cell fates. Nature 408: 53-56.

39. D'AdDA Di FAGAGNA, F. et al. 2003. A DNA damage checkpoint response in telomere-initiated senescence. Nature 426: 194-198.

40. Olson, M.O., M. Dundr \& A. SzeBeni. 2000. The nucleolus: an old factory with unexpected capabilities. Trends Cell Biol. 10: 189-196.

41. Hernandez-Verdun, D. 2006. The nucleolus: a model for the organization of nuclear functions. Histochem. Cell. Biol. 126: 135-148. Epub 2006 Jul 12.

42. BemilLeR, P.M. \& L.H. LEE. 1978. Nucleolar changes in senescing WI-38 cells. Mech. Ageing Dev. 8: 417-427.

43. Colombo, E., J.C. Marine, D. Danovi, et al. 2002. Nucleophosmin regulates the stability and transcriptional activity of p53. Nat. Cell. Biol. 4: 529533.

44. Daniely, Y., D.D. Dimitrova \& J.A. Borowiec. 2002. Stress-dependent nucleolin mobilization mediated by p53-nucleolin complex formation. Mol. Cell. Biol 22: 6014-6022.

45. BEREZNEY, R. 1991. The nuclear matrix: a heuristic model for investigating genomic organization and function in the cell nucleus. J. Cell. Biochem. 47: 109-123.

46. Berezney, R., M.J. Mortillaro, H. Ma, et al. 1995. The nuclear matrix: a structural milieu for genomic function. Int. Rev. Cytol. 162A: 1-65.

47. Martelli, A.M. et al. 1997. The nuclear matrix and apoptosis. Histochem. Cell. Biol. 108: 1-10.

48. Strouboulis, J. \& A.P. WolfFe. 1996. Functional compartmentalization of the nucleus. J. Cell. Sci. 109(Pt 8): 1991-2000.

49. Nickerson, J. 2001. Experimental observations of a nuclear matrix. J. Cell. Sci. 114: 463-474.

50. BARBORO, P. et al. 2002. Unraveling the organization of the internal nuclear matrix: RNA-dependent anchoring of NuMA to a lamin scaffold. Exp. Cell. Res. 279: 202-218.

51. HozaK, P., A.M. SAsseville, Y. Raymond \& P.R. CooK. 1995. Lamin proteins form an internal nucleoskeleton as well as a peripheral lamina in human cells. J. Cell. Sci. 108(Pt 2): 635-644.

52. NeRI, L.M. et al. 1999. Spatial distribution of lamin A and B1 in the K562 cell nuclear matrix stabilized with metal ions. J. Cell. Biochem. 75: 36-45.

53. Dell'Orco, R.T. \& W.L. Whittle. 1994. Nuclear matrix composition and in vitro cellular senescence. Exp. Gerontol. 29: 139-149.

54. DE LANGE, T. 1992. Human telomeres are attached to the nuclear matrix. EMBO J. 11: 717-724. 
55. LUDERUS, M.E. et al. 1996. Structure, subnuclear distribution, and nuclear matrix association of the mammalian telomeric complex. J. Cell. Biol. 135: 867-881.

56. WANG, G.S., W.J. LUO, W.J. PAN, et al. 1994. Association of chromosomal telomere DNA with nuclear matrix in HeLa cell. Sci. China B 37: 691-700.

57. Chaly, N., J.E. LitTle \& D.L. Brown. 1985. Localization of nuclear antigens during preparation of nuclear matrices in situ. Can J. Biochem. Cell Biol. 63(6): 644-653.

58. Petrova, N.V., O.V. Iarovaia, V.A. Verbovoy \& S.V. Razin. 2005. Specific radial positions of centromeres of human chromosomes X, 1, and 19 remain unchanged in chromatin-depleted nuclei of primary human fibroblasts: evidence for the organizing role of the nuclear matrix. J. Cell. Biochem. 96: 850-857.

59. Dijkwel, P.A. \& J.L. Hamlin. 1988. Matrix attachment regions are positioned near replication initiation sites, genes, and an interamplicon junction in the amplified dihydrofolate reductase domain of Chinese hamster ovary cells. Mol. Cell. Biol. 8: 5398-5409.

60. OKABE, J. et al. 2004. Limited capacity of the nuclear matrix to bind telomere repeat binding factor TRF1 may restrict the proliferation of mortal human fibroblasts. Hum. Mol. Genet. 13: 285-293.

61. Smilenov, L.B., S. Dhar \& T.K. PAndita. 1999. Altered telomere nuclear matrix interactions and nucleosomal periodicity in ataxia telangiectasia cells before and after ionizing radiation treatment. Mol. Cell. Biol. 19: 6963-6971.

62. Croft, J.A. et al. 1999. Differences in the localization and morphology of chromosomes in the human nucleus. J. Cell. Biol. 145: 1119-1131.

63. Margalit, A., S. Vlcek, Y. Gruenbaum \& R. Foisner. 2005. Breaking and making of the nuclear envelope. J. Cell. Biochem. 95: 454-465.

64. Gruenbaum, Y., A. Margalit, R.D. Goldman, et al. 2005. The nuclear lamina comes of age. Nat. Rev. Mol. Cell. Biol. 6: 21-31.

65. Stuurman, N., S. Heins \& U. Aebi. 1998. Nuclear lamins: their structure, assembly, and interactions. J. Struct. Biol. 122: 42-66.

66. Gruenbaum, Y. et al. 2003. The nuclear lamina and its functions in the nucleus. Int. Rev. Cytol. 226: 1-62.

67. Zastrow, M.S., S. VlCEK \& K.L. Wilson. 2004. Proteins that bind A-type lamins: integrating isolated clues. J. Cell. Sci. 117: 979-987.

68. Filesi, I., F. Gullotta, G. LAtTANZI, et al. 2005. Alterations of nuclear envelope and chromatin organization in mandibuloacral dysplasia, a rare form of laminopathy. Genomics. 23(2): 150-158.

69. Sullivan, T. et al. 1999. Loss of A-type lamin expression compromises nuclear envelope integrity leading to muscular dystrophy. J. Cell. Biol. 147: 913-920.

70. Goldman, R.D. et al. 2004. Accumulation of mutant lamin A causes progressive changes in nuclear architecture in Hutchinson-Gilford progeria syndrome. Proc. Natl. Acad. Sci. USA 101: 8963-8968.

71. Goldman, R.D., A.E. Goldman \& D.K. ShumaKer. 2005. Nuclear lamins: building blocks of nuclear structure and function. Novartis Found Symp. 264: 3-16; discussion 16-21: 227-230.

72. Spann, T.P., A.E. Goldman, C. WANG, et al. 2002. Alteration of nuclear lamin organization inhibits RNA polymerase II-dependent transcription. J. Cell. Biol. 156: 603-608.

73. HAQUE, F. et al. 2006. SUN1 interacts with nuclear lamin A and cytoplasmic nesprins to provide a physical connection between the nuclear lamina and the cytoskeleton. Mol Cell Biol 26: 3738-3751. 
74. Vergnes, L., M. Peterfy, M.O. Bergo, et al. 2004. Lamin B1 is required for mouse development and nuclear integrity. Proc. Natl. Acad. Sci. USA 101: 10428-10433. Epub 2004 Jul 1.

75. Padiath, Q.S. et al. 2006. Lamin B1 duplications cause autosomal dominant leukodystrophy. Nat. Genet. 38: 1114-1123.

76. AlsheImer, M. et al. 2004. Disruption of spermatogenesis in mice lacking A-type lamins. J. Cell. Sci. 117: 1173-1178.

77. Broers, J.L., F.C. Ramaekers, G. Bonne, et al. 2006. Nuclear lamins: laminopathies and their role in premature ageing. Physiol. Rev. 86: 9671008.

78. ScAfFidi, P. \& T. Misteli. 2006. Lamin A-dependent nuclear defects in human aging. Science. 312:1059-1063.

79. Dellaire, G. \& D.P. BazeTt-Jones. 2004. PML nuclear bodies: dynamic sensors of DNA damage and cellular stress. Bioessays 26: 963-977.

80. Chang, K.S., Y.H. FAn, M. AndreEFF, et al. 1995. The PML gene encodes a phosphoprotein associated with the nuclear matrix. Blood 85: 3646-3653.

81. Bridger, J.M. H. Herrmann, C. Munkel \& P.J. Lichter. 1998. Identification of an interchromosomal compartment by polymerization of nuclear-targeted vimentin. Cell Sci. 111:1241-1253.

82. Eskiw, C.H., G. Dellaire \& D.P. BazetT-Jones. 2004. Chromatin contributes to structural integrity of promyelocytic leukemia bodies through a SUMO-1independent mechanism. J. Biol. Chem. 279: 9577-9585.

83. Ruggero, D., Z.G. Wang \& P.P. PAndolfi. 2000. The puzzling multiple lives of PML and its role in the genesis of cancer. Bioessays 22: 827-835.

84. SeEler, J.S. \& A. DeJeAn. 1999. The PML nuclear bodies: actors or extras? Curr. Opin. Genet. Dev. 9: 362-367.

85. Boisvert, F.M., M.J. Hendzel \& D.P. BazetT-Jones. 2000. Promyelocytic leukemia (PML) nuclear bodies are protein structures that do not accumulate RNA. J. Cell. Biol. 148: 283-292.

86. LaMorte, V.J., J.A. Dyck, R.L. Ochs \& R.M. Evans. 1998. Localization of nascent RNA and CREB binding protein with the PML-containing nuclear body. Proc. Natl. Acad. Sci. USA 95: 4991-4996.

87. von Mikecz, A., S. Zhang, M. Montminy, et al. 2000. CREB-binding protein $(\mathrm{CBP}) / \mathrm{p} 300$ and RNA polymerase II colocalize in transcriptionally active domains in the nucleus. J. Cell. Biol. 150: 265-273.

88. Ching, R.W., G. Dellaire, C.H. Eskiw \& D.P. BAZETt-Jones. 2005. PML bodies: a meeting place for genomic loci? J. Cell. Sci. 118: 847-854.

89. WANG, J. et al. 2004. Promyelocytic leukemia nuclear bodies associate with transcriptionally active genomic regions. J. Cell. Biol. 164: 515-526.

90. Fleischer, S., S. Wiemann, H. Will \& T.G. Hofmann. 2006. PML-associated repressor of transcription (PAROT), a novel KRAB-zinc finger repressor, is regulated through association with PML nuclear bodies. Exp. Cell. Res. 312: 901-912.

91. Ferbeyre, G. et al. 2000. PML is induced by oncogenic ras and promotes premature senescence. Genes. Dev. 14: 2015-2027.

92. Pearson, M. et al. 2000. PML regulates p53 acetylation and premature senescence induced by oncogenic Ras. Nature 406: 207-210.

93. Mallette, F.A., S. Goumard, M.F. Gaumont-Leclerc, et al. 2004. Human fibroblasts require the Rb family of tumor suppressors, but not p53, for PMLinduced senescence. Oncogene 23: 91-99. 
94. Cremer, T., P. Lichter, J. Borden, et al. 1988. Detection of chromosome aberrations in metaphase and interphase tumor cells by in situ hybridization using chromosome-specific library probes. Hum. Genet. 80: 235-246.

95. Lichter, P., T. Cremer, J. Borden, et al. 1988. Delineation of individual human chromosomes in metaphase and interphase cells by in situ suppression hybridization using recombinant DNA libraries. Hum. Genet. 80: 224-234.

96. PInKel, D. et al. 1988. Fluorescence in situ hybridization with human chromosome-specific libraries: detection of trisomy 21 and translocations of chromosome 4. Proc. Natl. Acad. Sci. USA 85: 9138-9142.

97. Schardin, M., T. Cremer, H.D. Hager \& M. LANG. 1985. Specific staining of human chromosomes in Chinese hamster x man hybrid cell lines demonstrates interphase chromosome territories. Hum. Genet. 71: 281-287.

98. Abney, J.R., B. Cutler, M.L. Fillbach, et al. 1997. Chromatin dynamics in interphase nuclei and its implications for nuclear structure. J. Cell. Biol. 137: 1459-1468.

99. Chubb, J.R., S. Boyle, P. Perry \& W.A. Bickmore. 2002. Chromatin motion is constrained by association with nuclear compartments in human cells. Curr. Biol. 12: 439-445.

100. MARSHALL, W.F. et al. 1997. Interphase chromosomes undergo constrained diffusional motion in living cells. Curr. Biol. 7: 930-939.

101. Boyle, S. et al. 2001. The spatial organization of human chromosomes within the nuclei of normal and emerin-mutant cells. Hum. Mol. Genet. 10: 211-219.

102. Bridger, J.M., S. Boyle, I.R. Kill \& W.A. Bickmore. 2000. Remodelling of nuclear architecture in quiescent and senescent human fibroblasts. Curr. Biol. 10: $149-152$.

103. CRemer, T. et al. 2000. Chromosome territories, interchromatin domain compartment, and nuclear matrix: an integrated view of the functional nuclear architecture. Crit. Rev. Eukaryot. Gene Expr. 10: 179-212.

104. MANUELIDIS, L. 1985. Individual interphase chromosome domains revealed by in situ hybridization. Hum. Genet. 71: 288-293.

105. KReth, G., J. Finsterle, J. von Hase, et al. 2004. Radial arrangement of chromosome territories in human cell nuclei: a computer model approach based on gene density indicates a probabilistic global positioning code. Biophys. J. 86: 2803-2812.

106. Tanabe, H., F.A. Habermann, I. Solovei, et al. 2002. Non-random radial arrangements of interphase chromosome territories: evolutionary considerations and functional implications. Mutat. Res. 504: 37-45.

107. Meaburn, K.J., N. Levy, D. Toniolo \& J.M. Bridger. 2005. Chromosome positioning is largely unaffected in lymphoblastoid cell lines containing emerin or A-type lamin mutations. Biochem. Soc. Trans. 33: 1438-1440.

108. Meaburn, K.J., E. Cabuy, G. Bonne, et al. 2007. Primary laminopathy fibroblasts display altered genome organization and apoptosis Aging Cell. [Epub ahead of print].

109. BENN, P.A. 1976. Specific chromosome aberrations in senescent fibroblast cell lines derived from human embryos. Am. J. Hum. Genet. 28: 465-473.

110. Mukherjee, A.B., S. Thomas \& E. Schmitt. 1995. Chromosomal analysis in young vs. senescent human fibroblasts by fluorescence in situ hybridization: a selection hypothesis. Mech. Ageing Dev. 80: 11-23.

110. Corso, C. et al. 2005. Molecular cytogenetic insights into the ageing syndrome Hutchinson-Gilford Progeria (HGPS). Cytogenet. Genome Res. 111: 27-33. 